\title{
Patient Destination after Discharge from Intensive Care Units: Wards or Intermediate Care Units?
}

\author{
Maria Claudia Moreira da Silva ${ }^{1}$ \\ Regina Marcia Cardoso de Sousa² \\ Katia Grillo Padilha ${ }^{3}$
}

This study characterizes patients hospitalized in Intensive Care Units (ICUs) of hospitals that have intermediate units (IU) regarding their demographic and clinical data and identifies factors related to discharge from these units. This prospective longitudinal study involved 600 adult patients hospitalized in general ICUs in four hospitals in São Paulo, SP, Brazil. Demographic and clinical characteristics were similar to those found in other studies addressing patients hospitalized in ICUs. Factors associated with discharge from ICU to IU were: age $\geq 60$ years, diseases related to the nervous, circulatory or respiratory systems, originated from the IU, and Simplified Acute Physiologic Score II (SAPS II), Logistic Organ Dysfunction (LODS) and Nursing Activities Scores (NAS) at admission and discharge from the ICU. Age and risk of death at admission in the ICU, according to SAPS II, stood out as indicators of discharge to IUs in the Multiple Logistic Regression analysis.

Descriptors: Intensive Care Units; Patient Discharge; Workload; Severity of Illness Index. 


\title{
Destino do paciente após alta da unidade de terapia intensiva: unidade de internação ou intermediária?
}

Este estudo teve como objetivos caracterizar os pacientes internados em unidade de terapia intensiva (UTI) de hospitais com unidades intermediárias, quanto aos dados demográficos e clínicos, e identificar os fatores relacionados à alta para essa unidade. É estudo prospectivo longitudinal, com 600 pacientes adultos, internados em UTIs gerais de quatro hospitais do município de São Paulo. Nos resultados, as características demográficas e clínicas foram similares às descritas em outros estudos sobre pacientes em UTIs. Os fatores associados à alta para unidade intermediária foram: idade $\geq 60$ anos, antecedentes relacionados ao sistema nervoso, circulatório ou respiratório, procedência da unidade intermediária e valores do Simplified Acute Physiologic Score II (SAPS II), Logistic Organ Dysfunction (LODS) e Nursing Activities Score (NAS) na admissão e alta da UTI. Na análise de regressão logística múltipla a idade e o risco de morte na admissão, pelo SAPS II, destacaram-se como indicadores de alta para unidade intermediária.

Descritores: Unidades de Terapia Intensiva; Alta do Paciente; Carga de Trabalho; Índice de Gravidade de Doença.

\section{Destino del paciente después de recibir el alta médica de la unidad de cuidados intensivos: ¿unidad de internación o intermedia?}

\begin{abstract}
Este estudio tuvo como objetivos caracterizar a los pacientes internados en unidades de terapia intensiva (UTI) de hospitales con unidades intermediarias - en lo que se refiere a los datos demográficos y clínicos - e identificar los factores relacionados con el alta médica para esa unidad. Es estudio prospectivo longitudinal, con 600 pacientes adultos, internados en UTIs generales de cuatro hospitales del municipio de Sao Paulo. En los resultados, las características demográficas y clínicas fueron similares a las descritas en otros estudios sobre pacientes en UTIs. Los factores asociados con el alta hospitalaria para la unidad intermediaria fueron: edad $\geq 60$ años, antecedentes relacionados al sistema nervioso, circulatorio o respiratorio, procedencia de la unidad intermediaria y valores del Simplified Acute Physiologic Score II (SAPS II), Logistic Organ Dysfunction (LODS) y Nursing Activities Score (NAS) en la admisión y el alta de la UTI. En el análisis de regresión logística múltiple la edad y el riesgo de muerte en la admisión, por el SAPS II, se destacaron como indicadores del alta médica para la unidad intermediaria.

Descriptores: Unidades de Terapia Intensiva; Alta del Paciente; Carga de Trabajo; Índice de Severidad de la Enfermedad.
\end{abstract}

\section{Introduction}

Many factors complicate the decision to discharge patients hospitalized in Intensive Care Units (ICU) because of the great variability of clinical conditions observed in the patients of these units. It is frequently difficult to identify the indicators that define the "right place" for high-risk patients after their discharge. The scientific literature gives little emphasis on discharge criteria, which when well-defined, can result in less length of stay (LOS) in units with special care resources without compromising the quality of care ${ }^{(1)}$.

The characterization of patients in ICUs will aid the development of guidelines that determine admissions and discharges in these units because knowledge of the profile of critical patients favors the establishment of objective criteria. The application of objective criteria to admit and discharge ICU patients will promote a more rational use of beds and also avoid the exposure of patients to unnecessary risks through the reduction or 
increase of LOS in the unit(2). Therefore, being familiar with patients' conditions and these criteria is essential for nurses to plan and organize care in ICUs and hospitalizing units that receive these patients in their subsequent treatment.

The standards of ICU care have developed in recent decades and intensive monitoring is much more complex and diversified due to advances in technology. These conditions have increased the number of patients referred to ICUs, however, the need to contain costs has limited the expansion of ICUs physical facilities, which would allow a larger number of patients to be cared for in these units ${ }^{(3)}$. Hence, given the high cost of intensive care and the increased number of patients requiring ICU care, the optimized use of beds in this unit is crucial.

There is currently a tendency to create IUs in an attempt to rationalize the quantity of beds in ICUs and facilitate the work of multidisciplinary teams. IUs have facilities to care for individuals who still demand close nursing care that enables more economic and efficient use of space and services. In addition, as more advanced intermediate care and non-invasive monitoring technology are readily available, only a minority of patients needs to stay in ICUs only for monitoring ${ }^{(4)}$.

IUs, also called semi-intensive units, facilitate the management of services in terms of the rationalization of bed use, particularly in critical units, optimizing costs and promoting patients' well being since the presence of a companion or visitors is more frequently allowed.

In summary, this study addresses the concern for adequate transference of patients from ICUs to other units that meet their needs, the great concern related to costs and the quality of care of critical patients, which is directly related to nurses' activities due their role in planning the structure and processes developed in hospital units and also due to their participation in decision-making concerning patient discharge.

Based on these considerations, we deemed it important to describe the characteristics of patients hospitalized in the ICUs of hospitals having IUs and identify the factors related to the referral of patients to IU after they are discharged from ICUs.

\section{Method}

This is a prospective, longitudinal study of adult patients hospitalized in ICUs of two government hospitals and two non-government hospitals in Sao Paulo, SP, Brazil.
The followed criteria were considered in selecting the hospitals: located in the city of São Paulo, medium, large or extra large size, the presence of a general ICU and IU. The following exclusion criteria were also considered: pediatric intensive care unit, number of ICU beds less than $6 \%$ of the total number of the hospital beds and less than five beds in the IU (these criteria are based on recommendations of the Brazil Ministry of Health) ${ }^{(5)}$.

Thirty-five general hospitals with more than 50 beds for an adult population with ICU and IU were identified in the city of São Paulo in the DATASUS ${ }^{(6)}$ database. After analysis of the number of beds in these units, 15 hospitals were excluded according to the established criteria, leaving 20 hospitals. Of these, 12 hospitals were excluded after a visit in loco because they did not meet the study criteria.

The four facilities that had the largest number of beds in IU were selected among the eight remaining hospitals. Government and non-government facilities were separately analyzed and two hospitals of each administrative sphere remained.

The two selected government facilities were large and had only general units: adult IU and ICU. One of these was a university hospital, which had one active ICU bed for each 0.75 IU bed during the period of data collection. The rate was $1: 1.14$ for the other public hospital.

One of the selected non-governmental facilities was extra large and the other was large. The first hospital's ICU and IU were general and the large hospital had one cardiac unit in addition to two IUs for patients in general. The proportion of beds ICU/IU was $1: 2.18$, however, this is reduced to $1: 1.18$ when the beds of the specialized unit are excluded. The ratio of beds in the ICU to the IU was $1: 1.71$ beds in the extra large hospital.

It is worth noting that the teams of these facilities participating in this study did not rely on explicit criteria to designate patients for IU.

The sample was composed of 600 patients 18 years old or older, admitted in these ICUs from August 2006 to January 2007. The sample size was based on the study's proposal and computed by a professional specializing in sampling.

After the Ethics Research Committees approved the project (Processes no SMS52/2006; HU650/06; HSL2006/03 and AE06/510) and the nurses responsible for the ICUs were contacted, trained undergraduate nursing students initiated the data collection. 
Data were daily collected until a sample of 600 patients was achieved. Students went daily to the ICUs to look for new patients and follow-up on those already included in the study. In order to obtain data from the first and last 24 hours in the ICU, participants were followed-up with until they were discharged from the unit

Data were treated using Stata for Windows 8.0 and SPSS 13.0 for Windows software. Logistic regression was used to determine the factors associated with discharge from the IU. In the first stage, univariate logistic regression was carried out for each independent variable. These included age, gender, co-morbidities (classified according to the list of three characters of the International Classification of Diseases - ICD 10(7)), origin, and LOS in the ICU. The remaining variables were nursing workload measured by the Nursing Activities Score (NAS), risk of death according to the Simplified Acute Physiology Score II (SAPS II) and Logistic Organ Dysfunction Score (LODS).

Stepwise logistic regression was used and the variables that presented $p \leq 0.20$ in the univariate analysis were incorporated one by one into the models. The independent variables that achieved $p<0.05$ were kept in the final model. The model's goodness of fit was evaluated by the Hosmer-Lemeshow test.

\section{Results}

We observed among the clinical and demographic characteristics of patients (Table 1 ) that the average and median ages were 60.68 and 61.50 years old, respectively. If the two categories of individuals 60 years old or older are summed, the majority of the sample $(53.34 \%)$ is composed of elderly. Male patients predominated, representing $56.70 \%$ of the patients hospitalized in ICUs.

Regarding their origin, the majority were referred from the Emergency Unit (36.34\%) and a similar percentage of patients were sent from the Operating Room (35.50\%). Of the studied patients, 46 (7.66\%) were included in the category "others", the majority of which, 27 cases $(4.50 \%)$, came from other hospitals .

The average LOS in the ICU was 8.90 days ( \pm 10.90$)$, and individuals hospitalized for one or two days predominated (33.17\%). However, more than a quarter of patients $(28.50 \%)$ remained for 10 or more days in the ICU, of which $6.50 \%$ stayed for more than 30 days in this unit.
Table 1 - Demographic and clinical characteristics of patients ( $n=600)$. São Paulo, SP, Brazil 2006/2007

\begin{tabular}{lc}
\hline \multicolumn{1}{c}{ Variable } & $\mathbf{N}^{\circ}(\%)$ \\
\hline Age & $92(15.33)$ \\
$\geq 18$ and $<40$ & $188(31.33)$ \\
$\geq 40$ and $<60$ & $215(35.84)$ \\
$\geq 60$ and $<80$ & $105(17.50)$ \\
$\geq 80$ & \\
Gender & $340(56.70)$ \\
Male & $260(43.30)$ \\
Female & \\
Origin & $55(9.17)$ \\
Ward & $68(11.33)$ \\
IU & $218(36.34)$ \\
Emergency Unit & $213(35.50)$ \\
Operating Room & $46(7.66)$ \\
Others & \\
LOS in the ICU & $199(33.17)$ \\
1 to 2 days & $100(16.66)$ \\
3 to 4 days & $130(21.67)$ \\
5 to 9 days & $132(22.00)$ \\
10 to 29 days & $39(6.50)$ \\
$\geq 30$ days &
\end{tabular}

In the analysis of clinical data, the most frequent co-morbidities were related to diseases of the circulatory system (58\%) followed by endocrine, nutritional and metabolic diseases (28.66\%), neoplasia $(18.17 \%)$, diseases of the respiratory tract $(13.50 \%)$ and genitourinary tract $(13 \%)$. The frequency of other categories was lower than $10 \%$.

We note that $20 \%$ of the patients died during their hospitalization in the ICU. Of those who survived $(n=480), 64.60 \%$ were discharged to IUs and $32.90 \%$ were directly transferred to the wards, while $2.50 \%$ of the patients had other destinations.

In the total sample $(n=600)$, the average nursing workload in admission to ICU was $61.92 \%$ and on the last day of hospitalization in the ICU the average workload was $52.51 \%$. The average risk of death in the admission to the ICU was $25.50 \%$ according to SAPS II and $21.43 \%$ according to the LODS, values close to those verified at discharge, $23.14 \%$ and $20.73 \%$, respectively.

Differences were found in the analysis of survivors who were discharged from the ICU to the IU and wards as presented, in the Figures 1 and 2 . 


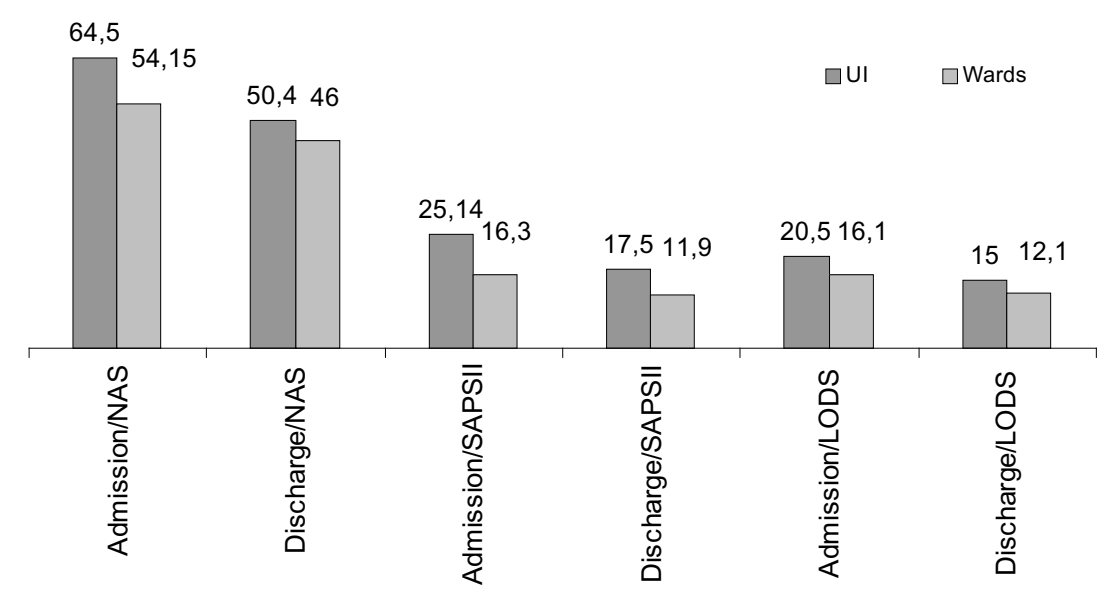

Figure 1 - Averages of NAS, SAPS II and LODS risk of death in admission and discharge of ICU according to patients' destination after discharge of ICU. São Paulo, Brazil 2006/2007

According to the data in Figure 1, the indicators of nursing workload and severity of illness were, both at discharge and admission, higher than for the group sent to the IU. The average nursing workload at admission into the ICU of patients sent to the IU was $64.50 \%$, that is, $10.5 \%$ higher than that of those who were sent to wards. The difference of the SAPS II average at admission also stood out in the comparison of patients sent to the two types of units and was approximately $9 \%$. In the comparison of average values at discharge, SAPS II presented a more marked difference in relation to NAS and LODS in the two groups sent to IU and wards.

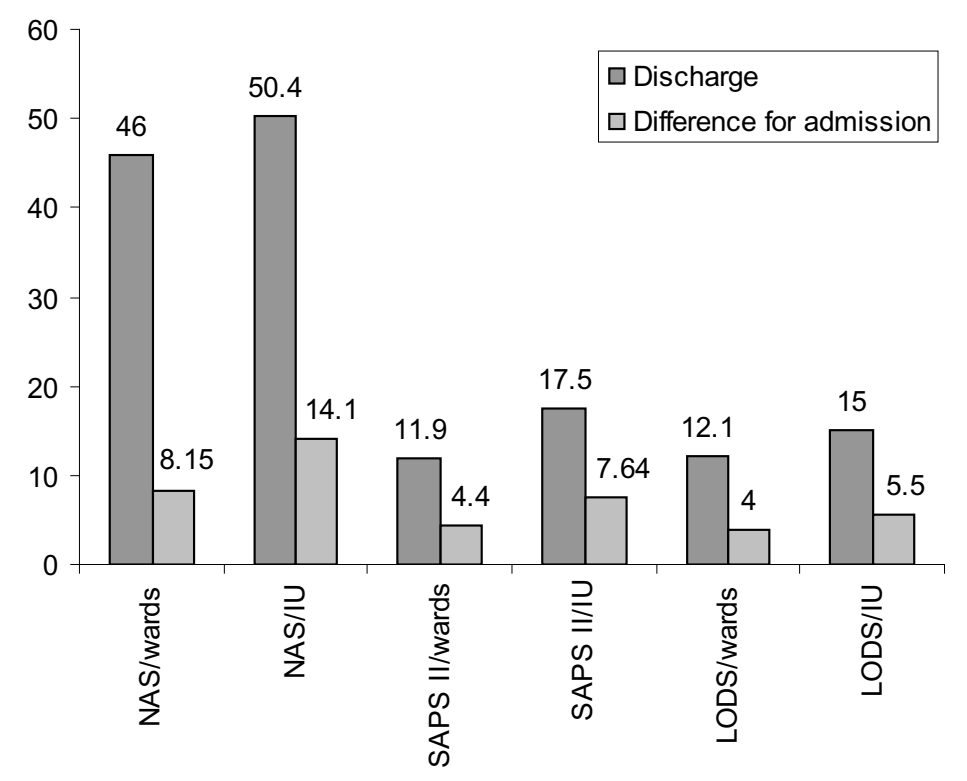

Figure 2 - Difference of NAS, SAPS II and LODS averages between admission and discharge from the ICU, according to the patients' destination to IU or wards. São Paulo, SP, Brazil 2006/2007 
Figure 2 shows that the reduction of indices was more marked in patients sent to the IU: 5.5 in relation to 4 in the LODS; 7.64 versus 4.4 in the SAPS II, and 14.1 and 8.15 in the NAS.

Table 2 shows that the characteristics of patients significantly associated with the patients' destination after ICUs were: age, origin from IU, values of SAPS II, LODS and NAS at admission and on the last day of hospitalization in the ICU, in addition to co-morbidities in the nervous (CID VI), circulatory (CID IX) and/or respiratory systems (CID X).
The table 3 shows the result of stepwise logistic regression: patients 60 years old or older had a 1.65 times greater chance of going to an IU than patients younger than 60 years. According to SAPS II, a patient's risk of death being $1 \%$ higher at admission meant an increase of $2 \%$ in the patient's chance of being sent to an intermediate unit $(\mathrm{OR}=1.02)$.

The Hosmer-Lemeshow test indicated that the logistic regression model was a good fit for the data $(p=0.7125)$.

Table 2 - Univariate logistic regression for destination after discharge (IU versus wards). São Paulo, SP, Brazil $2006 / 2007$

\begin{tabular}{|c|c|c|c|}
\hline Variable & Odds ratio (OR) & Confidence Interval $95 \%$ for OR & p-value \\
\hline Age (reference $<60$ years old) & 2.24 & $1.52-3.32$ & $<0.001$ \\
\hline Gender (reference: male) & 0.89 & $0.61-1.31$ & 0.559 \\
\hline \multicolumn{4}{|l|}{ Co-morbidities (reference: absence) } \\
\hline CID10-I & 1.45 & $0.66-3.18$ & 0.357 \\
\hline CID10-II & 1.14 & $0.68-1.90$ & 0.616 \\
\hline CID10-III & 1.54 & $0.41-5.77$ & 0.522 \\
\hline CID10-IV & 1.28 & $0.83-1.97$ & 0.267 \\
\hline CID10-V & 0.82 & $0.43-1.55$ & 0.542 \\
\hline CID10-VI & 3.03 & $1.15-8.00$ & 0.025 \\
\hline CID10-VII & - & - & \\
\hline CID10-VIII & - & - & \\
\hline CID10-IX & 1.60 & $1.08-2.35$ & 0.018 \\
\hline CID10-X & 2.44 & $1.26-4.72$ & 0.008 \\
\hline CID10-XI & 1.02 & $0.48-2.15$ & 0.964 \\
\hline CID10-XII & - & - & \\
\hline CID10-XIII & 1.80 & $0.37-8.75$ & 0.469 \\
\hline CID10-XIV & 0.99 & $0.56-1.76$ & 0.971 \\
\hline CID10-XV & - & - & \\
\hline CID10-XVIII & - & - & \\
\hline CID10-XIX & 1.15 & $0.35-3.79$ & 0.821 \\
\hline \multicolumn{4}{|l|}{ Origin (reference: wards) } \\
\hline IU & 7.11 & $1.84-27.43$ & 0.004 \\
\hline Operating Room & 0.57 & $0.27-1.20$ & 0.137 \\
\hline Emergency Unit & 0.95 & $0.45-2.03$ & 0.904 \\
\hline Others & 0.76 & $0.30-1.96$ & 0.573 \\
\hline LOS in ICU (days) & 1.01 & $0.99-1.03$ & 0.520 \\
\hline SAPS II admission (risk of death) & 1.03 & $1.01-1.04$ & $<0.001$ \\
\hline LODS admission (risk of death) & 1.02 & $1.00-1.03$ & 0.008 \\
\hline NAS admission & 1.03 & $1.01-1.04$ & $<0.001$ \\
\hline SAPS II discharge (risk of death) & 1.03 & $1.01-1.05$ & $<0.001$ \\
\hline LODS discharge (risk of death) & 1.02 & $1.00-1.04$ & 0.024 \\
\hline NAS discharge & 1.03 & $1.01-1.04$ & 0.001 \\
\hline
\end{tabular}

Table 3 - Multiple logistic regression for destination after discharge from ICU (IU versus wards). São Paulo, SP, Brazil 2006/2007

\begin{tabular}{|c|c|c|c|c|}
\hline Variable & Non-adjusted odds ratio (OR) & Adjusted odds ratio (OR) & Confidence interval $95 \%$ for OR & p-value \\
\hline Age (ref: $<60$ years old) & 2.24 & 1.65 & $1.07-2.54$ & 0.023 \\
\hline SAPS II admission (risk of death) & 1.03 & 1.02 & $1.01-1.03$ & 0.001 \\
\hline Hosmer-Lemeshow & $\chi^{2}=5.41$ & $p=0.7125$ & & \\
\hline
\end{tabular}




\section{Discussion}

The comparison of the characteristics of patients participating in this study with those observed in the literature that characterize patients hospitalized in ICUs $^{(2,8-10)}$ reveals that there is similarity in relation to age, gender, origin and co-morbidities, even when individuals are admitted in hospitals with IU.

Compared to wards, IUs present a structure that allows patients to be discharged earlier from ICUs. Therefore, the presence of this unit in a hospital should, in addition to diminishing the LOS in the ICU, increase the turnover of patients and diminish the repressed demand of patients for this unit. Additionally, earlier access to an ICU diminishes delays in the monitoring of patients and complex interventions reducing the mortality of patients. This study's results did not confirm the expectations of a lower average of LOS or mortality in ICUs that are backed-up by IUs, however, these two parameters have presented a great variability of results in the literature, which makes establishing a basis for comparison difficult(2,8-10).

Nonetheless, the majority of the survivors were transferred to IUs after discharge from ICUs (64.60\%). This result shows the importance of these units to care provided to individuals after they are discharged from ICUs and emphasizes the concept of progressive care.

Not all hospital facilities in the studied city have IUs. According to a search carried out in 2005, only 42 general hospitals in São Paulo city presented nonspecialized IU and only 35 of them cared for the adult clientele ${ }^{(6)}$.

This study used NAS as instrument to measure the nursing care workload and SAPS II and LODS were used as indicators of patients' risk of death at the admission and discharge of patients. Studies addressing indices of severity of patients' conditions and nursing workload can help to establish indicators of discharge from ICUs, though, these criteria obviously depend on other factors and on the course of the patient's development in relation to the treatment.

This study's results concerning NAS, SAPS II and LODS at admission into the ICU were compatible with data from the literature ${ }^{(8-9,11-14)}$. However, there are few studies providing values of these indicators in sequential days or at discharge from this unit.

In this study, patients sent to the IU were in a more critical condition and presented a heavier nursing workload at admission and discharge from the ICU (Figure 1).
However, these patients were the participants of the study who presented the most marked improvement during their stay in the ICU when compared to those sent to the wards (Figure 2). Consequently, the difference in the average of indicators of severity of illness and nursing workload at discharge from the ICU between the groups were less marked and the initial severity of a patient's condition stood out in relation to that presented at discharge from the unit.

Confirming these results in the identification of factors related to the discharge of patients from ICU sent to IUs, we observed that patients sent to the IUs differed from those sent to wards in terms of age, origin, co-morbidities related to the nervous, circulatory and respiratory systems, in addition to values of SAPS II, LOD and NAS at admission and discharge from the ICU. In the multivariate analysis, the following factors are highlighted: age and SAPS II at admission in the ICU.

In general, older patients with a poorer initial condition stood out in the group sent to IUs. Although the literature ${ }^{(15)}$ has shown that age does not determine poorer prognosis, due to factors associated with age, such as severity of acute disorders and co-morbidities, health professionals still have a perception that elderly patients respond less to certain therapeutic measures and therefore require more care.

In this study, age surpassed co-morbidities in decisions to refer patients to IUs, however, the study did not focus on the impact of the functional status of patients before hospitalization, a variable that might have contributed to the professionals' fear concerning the development of elderly patients.

Another piece of evidence in this study was in the relationship between the severity of illness and nursing workload. Even though both variables were associated with the indication of discharge to the IU severity prevailed in the final model.

It was observed that there was a dominance of severity of illness in relation to nursing workload in the referral of patients from ICUs to IUs, although the average of NAS at discharge from the ICU is noteworthy: $50.40 \%$ for those sent to IUs and $46 \%$ for those sent to wards. These percentages reveal high nursing workloads at the discharge of patients from this unit and show the need for caution in proportioning the nursing personnel in units that receive these patients. The observed rates suggest that patients on the last day of hospitalization in the ICU still require about half of the work produced by a nursing professional during a shift. 
Studies recently published in this periodical ${ }^{(16-18)}$ analyzed the nursing workload and severity of illness in ICUs and related them to age, mortality and costs. Although the unit to which patients were sent was not considered in the analysis of these studies, their results complement current study's results. From this perspective, we highlight the article that identifies factors related to workload and indicates severity, age and type of hospitalization in its results ${ }^{(18)}$. Age and severity of patient's conditions also stood out in the present study. Therefore, the study mentioned ${ }^{(18)}$ and the higher number of nursing professionals required by IUs in relation to wards $^{(4)}$ seems to corroborate the results found here.

Finally, it is worth noting that statistically significant differences were not found in relation to the LOS in the ICU between patients sent to wards and IUs. Thus, elderly patients who presented a higher risk of death at admission were those who probably benefited most from IUs in these hospitals as their LOS, in the ICU was similar to other patients.

IUs might have addressed the lack of beds in ICUs and moderate beliefs that underestimate the prognosis of elderly patients with severe conditions.

\section{Conclusions}

The characteristics of this patient group are similar to those found in other studies in relation to age, gender, origin, co-morbidities, severity of illness and nursing workload at admission into the ICU. Values of mortality and LOS in the ICU, which present great variability in the literature, were intermediate in this study compared to other investigations.

Older patients and those with a higher risk of death at admission into the ICU, according to the SAPS II, had a greater chance to be transferred to IUs. From a nursing point of view, these findings are relevant because they reiterate the need for an IU to give support to elderly patients who present extremely severe conditions - Given satisfactory development in the ICU, these patients should not be kept in this environment nor be sent to the wards under the risk of having undesirable outcomes such as being readmitted in the ICU or even death. These patients can benefit from care delivered in appropriate units, without an abrupt interruption in the delivery of care of which they still need. In summary, this study's findings suggest that the appropriate allocation of patients can contribute not only to their recovery but also to the reduction of intensive care costs.

\section{References}

1. Franklin C, Jackson D. Discharge decision-making in a medical ICU: characteristics of unexpected readmissions. Crit Care Med 1983; 11:61-6.

2. Silva MCM, Sousa RMC. Caracterização dos pacientes adultos e adolescentes das unidades de terapia intensiva do Município de São Paulo. Rev Paul Enferm. 2002; 21:50-7.

3. Miranda DR, de Rijk A, Schaufeli W. Simplified Therapeutic Intervention Scoring System: the TISS-28 items: results from a multicenter study. Crit Care Med. 1996; 24:64-73.

4. Cullen DJ, Nemeskal AR, Zaslavsky AM. Intermediate TISS: a new therapeutic Intervention Scoring System for non-ICU patients. Crit Care Med 1994; 22:1406-1.

5. Ministério da Saúde (BR). Secretaria de Vigilância Sanitária. Regulamento Técnico para o funcionamento dos serviços de tratamento intensivo. Portaria no 466, de 04 de junho de 1998. Brasília, DF; 1998.

6. Ministério da Saúde (BR). DATASUS. Indicadores: leitos. [acesso em: 28 setembro 2005]. Disponível em: http://cnes. datasus.gov.br/Mod_Ind_Tipo_Leito.asp.

7. Organização Mundial da Saúde (OMS). CID -10. Classificação estatística internacional de doenças e problemas relacionados à saúde. 3aed. São Paulo: OMS; 1996. v. 3.

8. Queijo AF. Estudo comparativo da carga de trabalho de enfermagem em unidades de terapia intensiva geral e especializadas, segundo o Nursing Activities Score (NAS). [tese]. São Paulo (SP): Escola de Enfermagem, Universidade de São Paulo; 2008.

9. Gonçalves LA, Padilha KG. Fatores associados à carga de trabalho de enfermagem em Unidade de Terapia Intensiva. Rev Esc Enferm USP. 2007;41(4):645-52.

10. Padilha KG, Sousa RMC, Kimura M, Miyadahira AMK, Cruz DALM, Vattimo MF, et al. Nursing workload in intensive care units: a study using the Therapeutic Intervention Scoring System-28 (TISS-28). Intensive Crit Care Nurs. 2007; 23(3):162-9.

11. Beck DH, Smith GB, Pappachan JV, Millar B. External validation of the SAPS II, APACHE II and APACHE III prognostic models in South England: a multicentre study. Intensive Care Méd. 2003; 29:249-56.

12. Conishi RMY, Gaidzinski RR. Nursing Activities Score (NAS) como instrumento para medir carga de trabalho de enfermagem em UTI Adulto. Rev Esc Enf USP. 2007; 41:346-354, 2007.

13. Nogueira LS, Sousa RMC, Domingues CA. Severity of trauma victims admitted in intensive care units: comparative study among different indexes. Rev Latino-am Enfermagem 2009; 17(6): 1037-42.

14. Timsit JF, Fosse JF, Troché G, Lassence A, Alberti C, GarrousteOrgeas $M$, et al. Calibration and discrimination by daily Logistic Organ Dysfunction Scoring comparatively with daily Sequential Organ Failure Assessment scoring for predicting hospital mortality in critically ill patients. Crit Care Med. 2002; 30:2003-13. 
15. Feijó CAR, Bezerra ISAM, Peixoto AA Jr, Meneses FA. Morbimortalidade do idoso internado na unidade de terapia intensiva de hospital universitário de Fortaleza. Rev Bras Ter Intensiva. 2006; 18(3):263-7.

16. Elias ACGP, Tiemi M, Cardoso LTQ, Grion CMC. Aplicação do sistema de pontuação de intervenções terapêuticas (TISS 28) em unidade de terapia intensiva para avaliação da gravidade do paciente. Rev Latino-am Enfermagem. 2006; 14(3):324-9.
17. Telles SCR, Castilho V. Custo de pessoal na assistência direta de enfermagem em unidade de terapia intensiva. Rev Latino-am Enfermagem. 2007; 15(5):1005-9.

18. Sousa CR de, Gonçalves LA, Toffoleto MC, Leão K, Padilha KG. Preditores da demanda de trabalho de enfermagem para idosos internados em unidade de terapia intensiva. Rev Latinoam Enfermagem. 2007; 16(2):218-23. 